\title{
A Vibration-Based Method for the Measurement of Subgrade Soil Scaling Factor
}

\author{
Guina WANG ${ }^{1,2 *}$, Dakai LIANG ${ }^{1}$, and Junfan YAN ${ }^{3}$ \\ ${ }^{1}$ State Key Laboratory of Mechanics and Control of Mechanical Structures, Nanjing University of Aeronautics and \\ Astronautics, Nanjing 210016, China \\ ${ }^{2}$ College of Mechanical and Electrical engineering, Soochow University, Suzhou 215021, China \\ ${ }^{3}$ School of Earth Sciences and Engineering, Nanjing University, Nanjing 210093, China \\ *Corresponding author: Guina WANG～E-mail: ntyjxx@126.com
}

\begin{abstract}
The subgrade soil scaling factor (SSSF) shows the basic properties of soil such as stiffness, gravimetry, density, and particle distribution, which are essential for disaster prediction and geotechnical engineering activities. In this paper, methods used for soil properties analysis are firstly summarized, and then a fiber Bragg grating (FBG) sensing technology is introduced. In order to acquire the properties and mechanical characteristics of soil accurately, a vibration-based method is presented, and an experiment for judging the properties of soil is conducted. As for the experiment, an FBG sensor is adhered to the upside of the vibration rod to measure its fundamental frequency. The rod vibrates freely at different-depth level of soil, and the changed data of wavelength from the FBG sensor are carefully collected. The Winkler spring model is used to analyze the relationship between the fundamental frequency and stiffness of soil. The results of this experiment suggest that data collected from FBG sensor can reflect vibration situation clearly and quantitatively. Thus the SSSF value can be calculated from the frequency-stiffness equation. The experimental results are almost identical with the theoretical derivation results. This confirms that the method presented in the paper can determine the SSSF effectively.
\end{abstract}

Keywords: Vibration sensor; cantilever beam; Winkler reaction spring model; subgrade soil scaling factor

Citation: Guina WANG, Dakai LIANG, and Junfan YAN, “A Vibration-Based Method for the Measurement of Subgrade Soil Scaling Factor," Photonic Sensors, 2018, 8(4): 375-383.

\section{Introduction}

The preliminary problem with almost all kinds of geotechnical engineering is how to obtain the properties and mechanical characteristics of soil accurately. At present, methods for researching and analyzing soil are mainly indoor experiments and in-situ measurements. Firstly, appropriate methods and techniques to acquire the characters of soil is needed, and only based on it, the data analysis may be more consistent with the actual situation.
As an index to describe the basic physical properties of soil such as stiffness, gravimetry, density, and particle distribution, the subgrade soil scaling factor (SSSF) is widely used in geotechnical engineering research and construction. A review of technical literatures reveals that the methods for measuring SSSF were developed over the past years, and many of them were based on the Winkler reaction spring model to analyze the soil structure. Analysis of laterally loaded beam is initially based on the model of representing soil by

Received: 16 April 2018 / Revised: 20 June 2018

(C) The Author(s) 2018. This article is published with open access at Springerlink.com

DOI: $10.1007 / \mathrm{s} 13320-018-0505-\mathrm{x}$

Article type: Regular 
some discrete springs using Winkler's beam on the elastic foundation approach [1]. Later on, free vibration analysis of beams on elastic foundation was studied using the Winkler model in [2-6]. Thambiratnam and Zhuge [7, 8] set up a foundation model by using the Winkler springs model to analyze the beam and foundation whose properties changed along the length of beam. Further studies are conducted to reveal the response of beams on an elastic foundation subjected to static or dynamic loads. Zhong et al. [9] presented a simplified method for the lateral response of composite caisson-piles foundations based on the dynamic Winkler model. Gao et al. [10] proposed a mixed finite element method for solving contact problems of the largely deformed beam on the elastic foundation. Hajialilue-Bonab et al. [11] introduced the relationship of damping with depth during vibration of pile and presented an equation of the movement of a beam equivalent to the pile under dynamic loading. Zarafshan et al. [12] analyzed a vibration-based method to monitor the fundamental frequency of the vibration sensor rod so as to measure the bridge scour.

In recent years, the optical fiber sensing technology provides a new technology and method to analyze the soil in geotechnical fields [13, 14]. The fiber Bragg grating (FBG) sensor is especially used. FBG sensors have several technical advantages in sensitivity, long-distance measurement, multiplexing of sensors, and immunity to electromagnetic noise compared with conventional electrical sensors [15]. Due to these advantages, FBG sensors have been widely used in geotechnical fields.

Rodrigues et al. [16] described an FBG-based system with embedded displacement and strain transducers for long-term monitoring of structural performance of concrete. Zhou et al. [17] developed an FBG sensing system for scour monitoring of foundations of bridge piers and abutments. Li et al. [18] performed an investigation onto the feasibility of the FBG-based monitoring system mounted in a building during construction. Wei et al. [19, 20] developed a real-time wheel defect detection system by deploying FBG sensors on rail tracks of the Hong Kong mass transit railway to gain the track strains upon wheel-rail interaction and generate a reliable condition index which can reflect the wheel condition. Pei et al. [21, 22] proposed an FBG-based in-place inclinometer for lateral displacement measurement of slopes in accordance with the classical indeterminate beam theory which was successfully installed in a slope in China for long-term displacement monitoring. Kister et al. [23] deployed FBG sensors in reinforced concrete foundation piles for strain and temperature monitoring and structural health condition assessment.

Though many literatures were studied based on the Winkler model or FBG sensors, few researches were carried on soil properties and then for geotechical engineering activities and disaster prediction. In this paper, a new method for measuring SSSF is introduced. The FBG vibration sensor rod with an initial pressure is driven into soil to measure the change of wavelength. Therefore, the fundamental frequency of the sensor rod can be obtained. Furthermore, the Winkler reaction spring model is constructed to analyze the stiffness distribution of soil, and the method for computing the SSSF is described.

\section{FBG sensor}

The FBG sensor is made by exposing the core of a single-mode fiber to a periodic pattern of intense ultraviolet light. When the fiber is illuminated by ultraviolet light at a certain wavelength, the refractive exponent of the fiber will be changed. As each periodic refraction changes, a small amount of light is reflected. All the reflected light signals combine to one large reflection at a particular wavelength. The wavelength at which this reflection occurs is called the Bragg wavelength.

The Bragg wavelength $\lambda_{B}$ can be calculated by

$$
\lambda_{B}=2 n_{\text {eff }} \Lambda
$$

where $n_{\text {eff }}$ is the effective index of refraction, and 
$\Lambda$ is the grating period. The variation of the Bragg wavelength can be expressed as

$$
\Delta \lambda_{B}=\lambda_{B}\left\{(\alpha+\xi) \Delta T+\left(1-p_{e}\right) \Delta \varepsilon\right\}
$$

where $\Delta \varepsilon$ is the strain variation, $\Delta T$ is the temperature change, $\alpha$ is the coefficient of the thermal expansion, $\xi$ is the thermo optic coefficient, and $p_{e}$ is the strain optic coefficient [24].

The relationship between the strain $\varepsilon$ and the wavelength shift $\Delta \lambda_{B}$ is established through calibration and defined by the gauge factor $G_{F}$.

$$
\varepsilon=\frac{\Delta \lambda_{B} / \lambda_{B}}{G_{F}} .
$$

The calibration process for any of the sensors is determined by mounting the sensor to a calibration beam to generate a known strain $\varepsilon$. The wavelength change is measured and the corresponding gage factor is calculated by (3). Though the gage factor for typical optical fibers can be computed through known properties of the optical core, calibration is necessary to reduce errors [25].

\section{Vibration sensor}

The proposed sensor is shown in Fig. 1. An FBG sensor is adhered on the surface of a rod by epoxy glue and connected with an interrogator via fiber optic cable. The rod is driven into soil vertically. It seems like a cantilever beam. The principle of detecting soil and analyzing the properties of soil is based on measuring the vibration fundamental frequency of the cantilever beam.

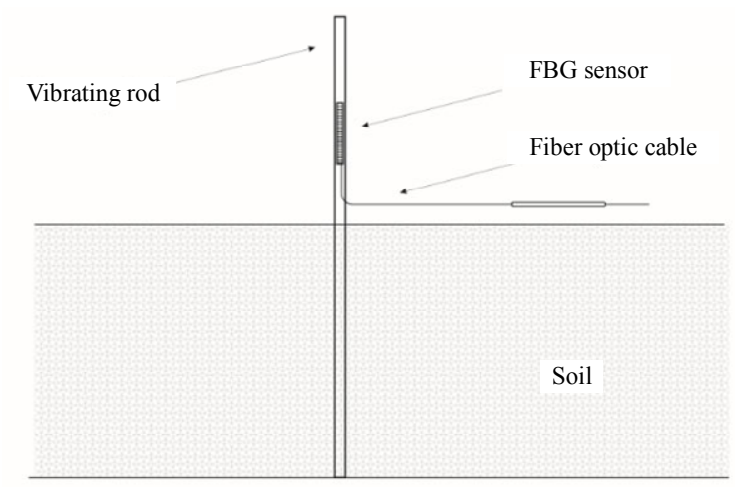

Fig. 1 Vibration sensor structure.
The partial differential equation governing the motion $u(x, t)$ of a beam subjected to dynamic pressure $p(x, t)$ is as

$$
\begin{aligned}
& \rho(x) A(x) \frac{\partial^{2} u(x, t)}{\partial t^{2}}+\frac{\partial^{2}}{\partial x^{2}}\left[E I(x) \frac{\partial^{2} u(x, t)}{\partial x^{2}}\right] \\
& =p(x, t)
\end{aligned}
$$

where $\rho, A, x, E, I$, and $t$ are density, area of cross-section, position along the length of cantilever beam, modulus of elasticity, moment of inertia, and time, respectively.

Assuming $p(x, t)=0$ and $u(x, t)=Y(x) F(t)$, the partial differential equation shows the free vibration of cantilever beam, and it can be concluded that

$$
\frac{d^{2} F(t)}{d t^{2}}+\omega^{2} F(t)=0
$$

where $\omega$ is the fundamental natural frequency of the beam.

For the cantilever beam, after substitution of boundary conditions as $Y(0)=0, \frac{d Y(0)}{d x}=0$, $\frac{d^{2} Y(l)}{d x^{2}}=0$, and $\frac{d^{3} Y(l)}{d x^{3}}=0$, the frequency equation is as follows:

$$
\cos \left(\beta_{n} l\right) \cosh \left(\beta_{n} l\right)=-1
$$

where $\beta_{n}^{4}=\frac{\omega_{n}^{2} \rho A}{E I}$.

The frequency of the beam can be calculated as follows:

$$
\omega_{n}=\beta_{n}^{2} \sqrt{\frac{E I}{\rho A}}, n=1,2, \cdots
$$

By solving (6), the eigenvalues are calculated as shown in Table 1.

Table 1 Eigenvalues of characteristic equation.

\begin{tabular}{rrrrc}
\hline$\beta_{1} l$ & $\beta_{2} l$ & $\beta_{3} l$ & $\beta_{4} l$ & $\beta_{5} l$ \\
\hline 1.875 & 4.694 & 7.855 & 10.996 & 14.137 \\
\hline
\end{tabular}

So, the fundamental natural frequency for cantilever beam is as follows:

$$
\omega_{1}=\frac{3.516}{l^{2}} \sqrt{\frac{E I}{\rho A}} .
$$

For the known properties $(E, I, \rho$, and $A$ ) 
of a certain beam, an increase in cantilever length $l$ results in a corresponding decrease in the natural frequency of the beam. For the sensor rod vibrating in soil shown in Fig. 1, it is not completely the same as free vibration of a cantilever beam, because the cantilever beam is not fixed on the interface between soil and air but beneath a certain depth of soil which makes the effective length of the cantilever beam longer than length $l$. For this reason, a modification of (8) is made as

$$
\omega_{1}=\frac{3.516}{(l+c L)^{2}} \sqrt{\frac{E I}{\rho A}}
$$

where $L$ is the total length of the sensor rod and $c$ is a constant to amend the length of cantilever beam.

The relationship between the fundamental frequency and cantilever length after amending are shown in Fig. 2.

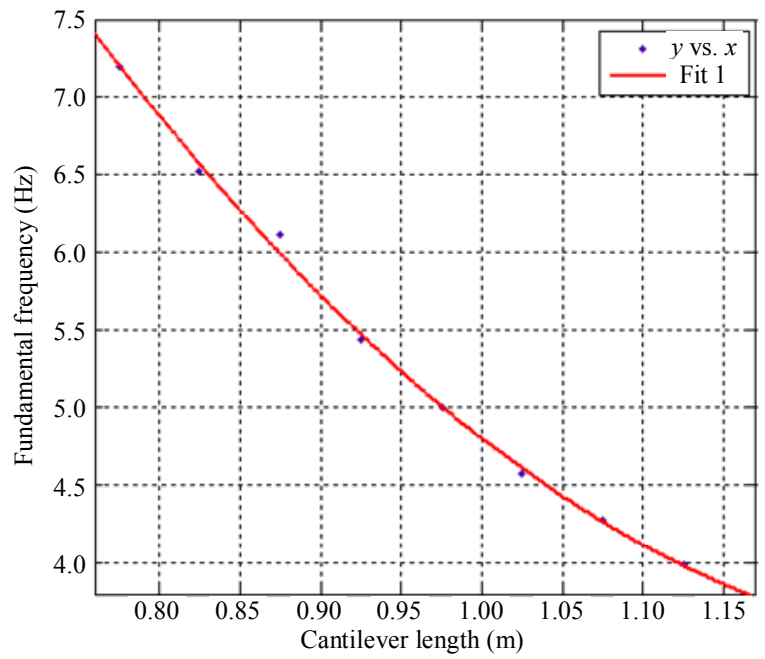

Fig. 2 Relationship between fundamental frequency and cantilever length of the beam.

The vibration response figure at some frequency is portrayed in Fig. 3. It can be seen from Fig. 3 that the experimental system is an under critically damped system.

The equation of this system can be calculated by

$$
f_{D}=\frac{\omega_{D}}{2 \pi}
$$

where $\omega_{D}$ is the free vibration frequency of the damped system.

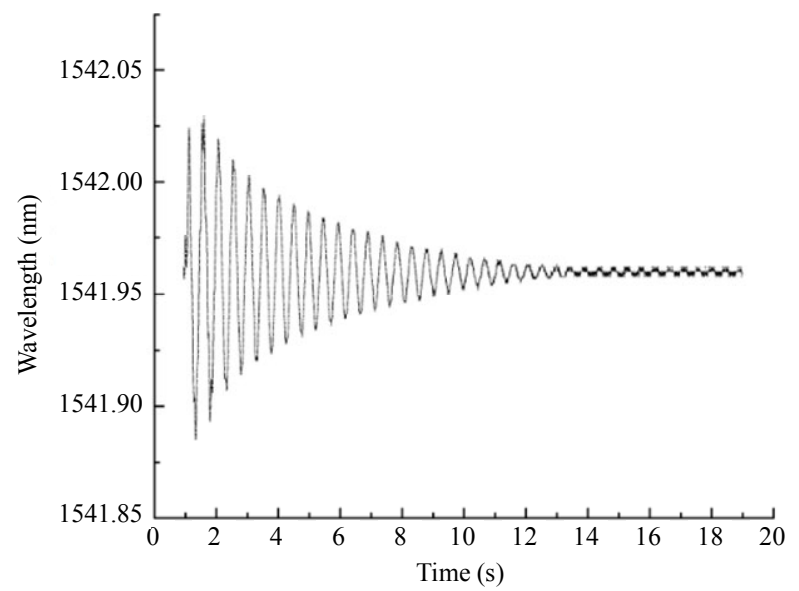

Fig. 3 Vibration responses at certain frequency.

Comparing $f_{D}$ with the undamped vibration frequency, we can portray the curves as shown in Fig. 4. As can be seen from Fig. 4, the two curves agree fairly well. So the system can be assumed as a freely undamped vibration system.

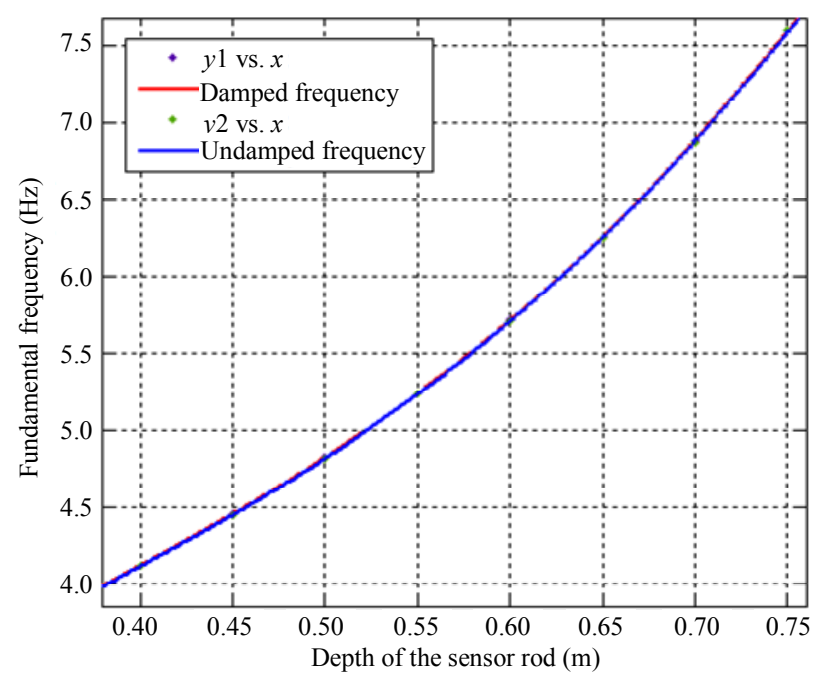

Fig. 4 Frequency comparison of damped and undamped vibration.

\section{Methods}

We construct the analogy model from two segments. The soil sensor rod has a total length of $L$. For the segment above the soil which has the length of $l$, an amended cantilever beam is applied as explained previously. For the segment embedded in the soil, the Winkler reaction spring model is used to describe the operational principle of the soil sensor as shown in Fig. 5. Realistic establishment of the relationship between the fundamental frequency and 
sensor length provides a practical tool for the calibration of the Winkler spring model. The process is described herein.

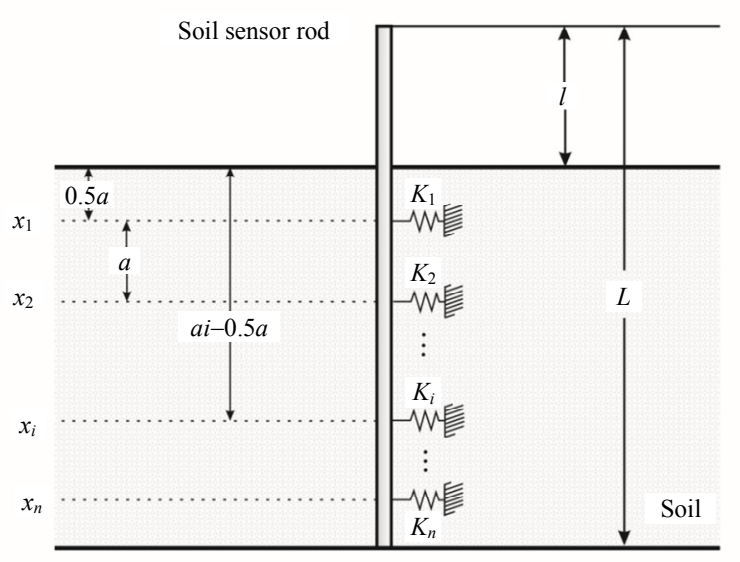

Fig. 5 Winkler spring model.

Assuming the spring constant $K$ and the embedded depth of the sensor $\operatorname{rod} x$, the pressure $p(x)$ is expressed as follows:

$$
p(x)=K x \text {. }
$$

According to the Winkler spring model, the embedded segment of the sensor rod is constrained by $n$ discrete springs with stiffness $K_{i}$, which can be calculated as

$$
K_{i}=k^{*} x_{i} D a
$$

where $x_{i}$ is the depth embedded in the soil, $k^{*}$ is SSSF, $D$ is the diameter of the sensor rod, and $a$ is the soil depth of each spring, as shown in Fig. 5.

It is then possible to determine the relationship between the fundamental frequency of vibration and the stiffness of Winkler springs.

The equation of motion of the sensor rod can be expressed as

$$
\mathbf{m} \ddot{\mathbf{v}}+\mathbf{k v}=\mathbf{0}
$$

where $\mathbf{m}$ is the mass matrix, $\mathbf{k}$ is the stiffness matrix, $\mathbf{0}$ is a zero vector, and $\ddot{\mathbf{v}}$ and $\mathbf{v}$ are the acceleration vector and displacement vector, respectively.

The vibration of the sensor rod can be expressed as

$$
\mathbf{v}(t)=\hat{\mathbf{v}} \sin (\omega t+\theta)
$$

where $\hat{\mathbf{v}}$ represents the shape of the system, and $\theta$ is a phase angle.

It is possible to determine the fundamental frequency of vibration by solving (15).

$$
\left[\mathbf{k}-\omega^{2} \mathbf{m}\right] \hat{\mathbf{v}}=0 \text {. }
$$

which is called an eigenvalue problem. So it can be concluded that

$$
\left\|\mathbf{k}-\omega^{2} \mathbf{m}\right\|=0
$$

which is called the frequency equation of the system [26].

\section{Experimental program}

The experiment is constructed by filling soil into a chamber which consists a $0.75 \mathrm{~m}$ high, $0.61 \mathrm{~m}$ wide, and $0.91 \mathrm{~m}$ long cuboid tank. The finely granulated silica sand is used in the experiment. Some physical properties of this sand are shown in Table 2.

Table 2 Some physical properties of the sand.

\begin{tabular}{cccc}
\hline $\begin{array}{c}\text { Diameter } \\
(\mathrm{mm})\end{array}$ & $\begin{array}{c}\text { Density } \\
\left(\mathrm{g} / \mathrm{cm}^{-3}\right)\end{array}$ & $\begin{array}{c}\text { Compression } \\
\text { modulus }(\mathrm{MPa})\end{array}$ & $v$ \\
\hline 0.2 & 1.506 & 15 & 0.2 \\
\hline
\end{tabular}

A vibration sensor rod is driven into soil. The length of the sensor rod is $1.525 \mathrm{~m}$, and the diameter is $0.01 \mathrm{~m}$. The rod is made with aluminum alloy, and the density is $2.54 \mathrm{~g} / \mathrm{cm}^{-3}$. The device SM130 is applied for demodulating the wavelength of the FBG sensor. The time domain signals are achieved, and it could be changed to frequency domain through fast Fourier transform (FFT). The experimental setup is shown in Figs. 6 and 7.

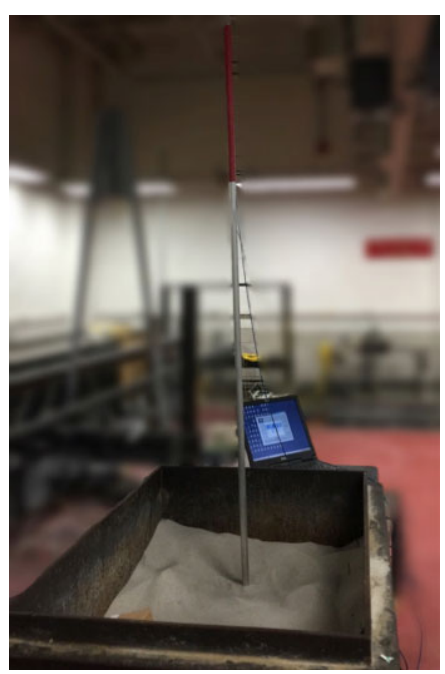

Fig. 6 Indoor experimental setup. 


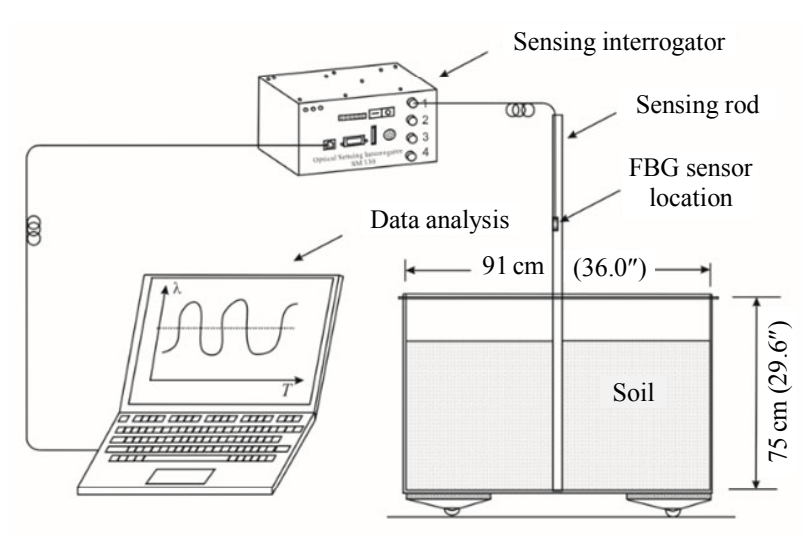

Fig. 7 Laboratory experimental setup.

We record the initial length of the cantilever beam. Then we manually remove the soil at $0.05 \mathrm{~m}$ step. Each time, we excite the sensor rod to vibrate freely by giving it a slight horizontal displacement and then releasing it. Then, we write down the removed depth of the soil and the frequency achieved from the FBG sensor after demodulating by SM130. For each frequency, the Winkler spring model is applied to get the SSSF, $k^{*}$, by solving (16) and (12). It is then possible to construct the relationship between fundamental frequency, $f$, and SSSF, $k^{*}$. A given value of $k^{*}$ indicates the properties of soil, as shown in Table 3 . So it is very important to measure the SSSF value for a judgment of the properties of soil.

Table 3 Reference $k^{*}$ values of the soil.

\begin{tabular}{ccc}
\hline No. & Sorts of soil & $k^{*}\left(\mathrm{kN} / \mathrm{m}^{4}\right)$ \\
\hline 1 & Silt ( mud) & $3000 \sim 5000$ \\
2 & Silt & $5000 \sim 10000$ \\
3 & Medium sand & $10000 \sim 20000$ \\
4 & Fine sand & $10000 \sim 20000$ \\
5 & Coarse sand & $20000 \sim 30000$ \\
6 & Gravel & $30000 \sim 80000$ \\
7 & Gravel sand & $30000 \sim 80000$ \\
8 & Pebble & $30000 \sim 80000$ \\
\hline
\end{tabular}

\section{Results and discussion}

\subsection{Wavelength change and fundamental frequency}

For a certain length of cantilever or a certain depth of the rod, the change of wavelength over time can be obtained by SM130 as shown in Fig. 8(a). As shown in Fig. 8(a), the wavelength of the FBG sensor varies periodically and sinusoidally though the amplitude reduces. It is pointed out that the reduction in amplitude caused by damping of soil affects little on the fundamental frequency discussed earlier. So the system, can be assumed as a freely undamped vibration system and the frequency could be achieved by FFT [Fig. 8(b)]. It is easy to read the value of frequency from Fig. 8(b). For different lengths of cantilever or different depths of the rod, the frequencies could be achieved correspondingly. At last, experimental data including fundamental frequency, cantilever length, and the removed depth of soil are recorded in Table 4.

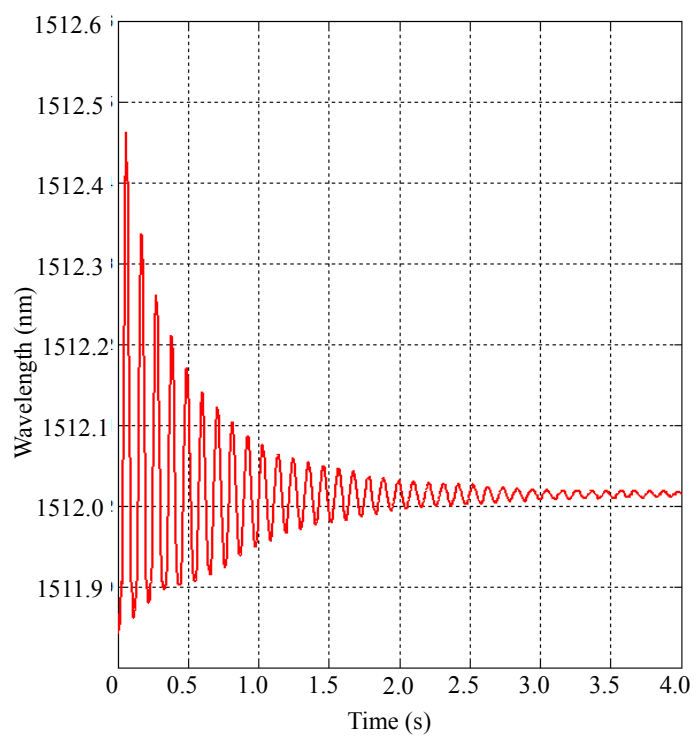

(a)

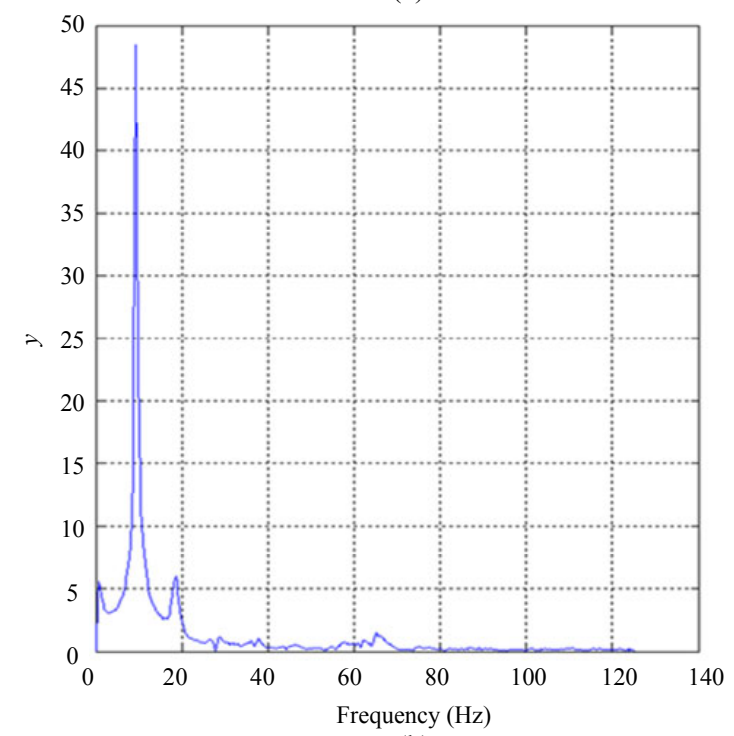

(b)

Fig. 8 Sensor rod vibration with (a) FBG wavelength change and (b) FFT. 
Table 4 Experimental data record.

\begin{tabular}{cccc}
\hline$l(\mathrm{~m})$ & $\begin{array}{c}\text { Removed soil } \\
\text { depth }(\mathrm{m})\end{array}$ & $\begin{array}{c}\text { Rod depth under the } \\
\text { soil }(\mathrm{m})\end{array}$ & $\begin{array}{c}\text { Measured } \\
\text { frequency }(\mathrm{Hz})\end{array}$ \\
\hline 0.775 & 0.00 & 0.75 & 7.20 \\
0.825 & 0.05 & 0.70 & 6.52 \\
0.875 & 0.10 & 0.65 & 6.11 \\
0.925 & 0.15 & 0.60 & 5.43 \\
0.975 & 0.20 & 0.55 & 5.00 \\
1.025 & 0.25 & 0.50 & 4.57 \\
1.075 & 0.30 & 0.45 & 4.28 \\
1.125 & 0.35 & 0.40 & 3.99 \\
\hline
\end{tabular}

6.2 Measured frequency and the computed frequency

We could portray the curve of the measured frequency over the rod depth according to Table 4.

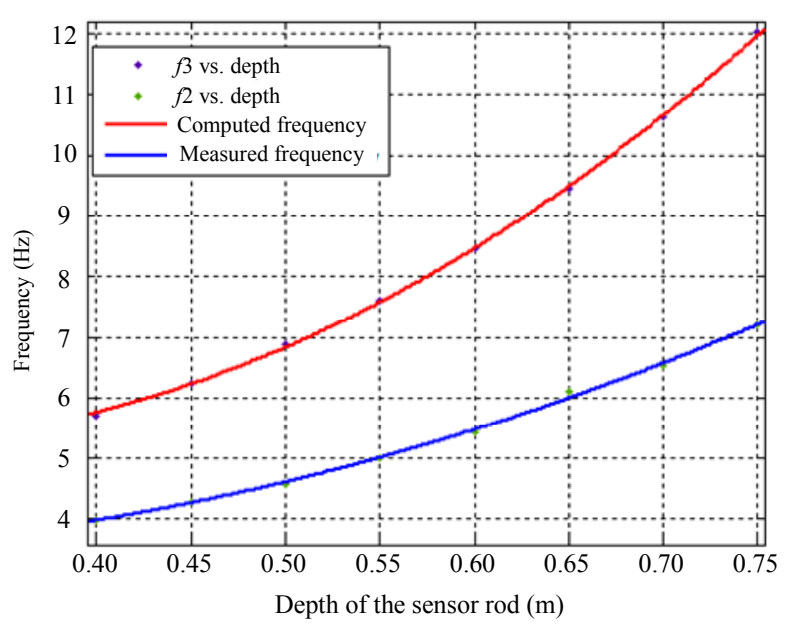

(a)
Also, the frequency based on (8) in different depths of the rod could be computed. The measured frequency and the computed frequency are presented in Fig. 9(a). As can be seen from Fig.9(a), there is a noticeable difference between these two curves. It is because the cantilever beam in this experiment is not fixed on the interface of soil and air but beneath a certain depth of soil. We thus suggest that the frequency should be calculated according to (9), and again the comparison curves are shown in Fig. 9(b). It is obvious that the difference between two curves in Fig. 9(b) decreases significantly. These two curves agree well.

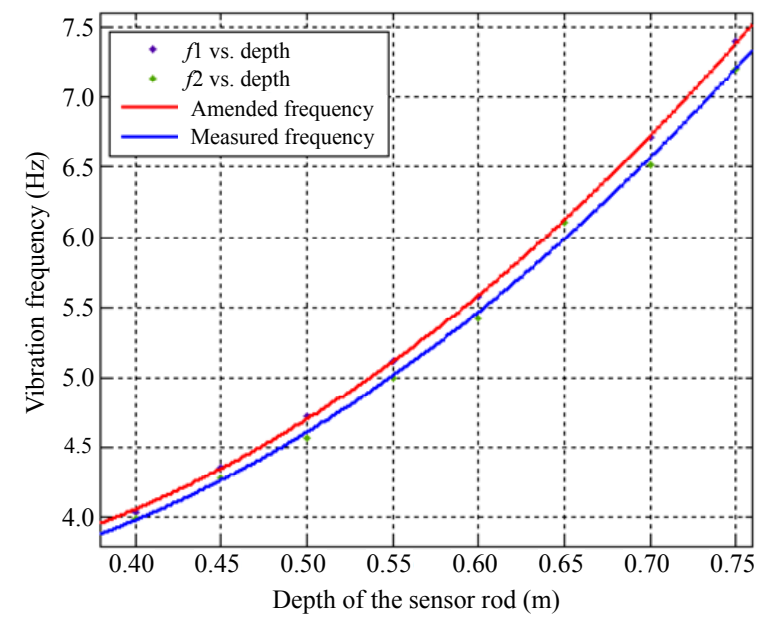

(b)

Fig. 9 Comparison of measured frequency with (a) computed frequency and (b) computed frequency (amended).

\subsection{Fundamental frequency and SSSF}

For each measured frequency, the Winkler spring model is applied to get the value of $k^{*}$ according to (12) and (16). And, then, the relationship between the fundamental frequency $f$ and SSSF $k^{*}$ could be portrayed in Fig. 10. It can be seen from Fig. 10 that an increase in the fundamental frequency results in the corresponding increase in SSSF. It can also be seen from Fig. 10 that the range of the SSSF we measured is between $9700 \mathrm{kN} / \mathrm{m}^{4}$ and $16140 \mathrm{kN} / \mathrm{m}^{4}$. The results indicate that the measured soil is either the medium or fine sand based on Table 3 . Additionally, the relationship between the fundamental frequency and the depth of the sensor rod (or removed soil depth) could also be portrayed, as shown in Fig. 11.

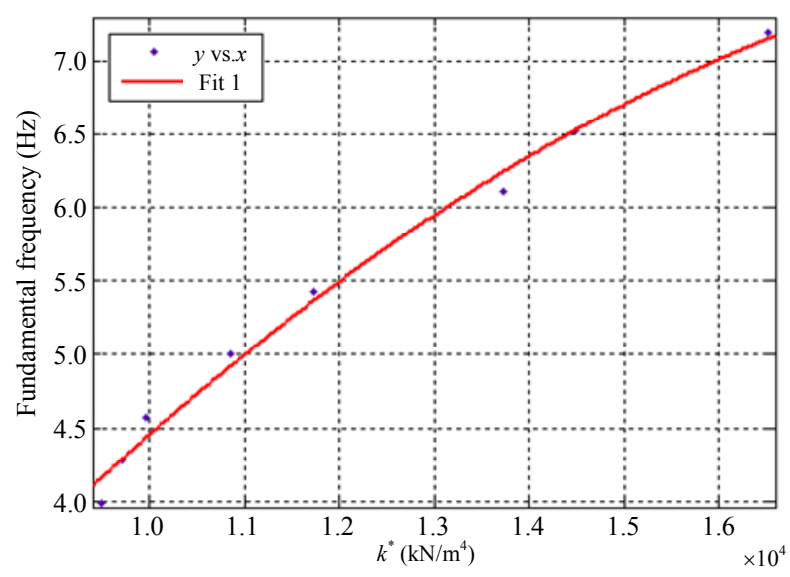

Fig. $10 k^{*}$ values as a function of the fundamental frequency. 


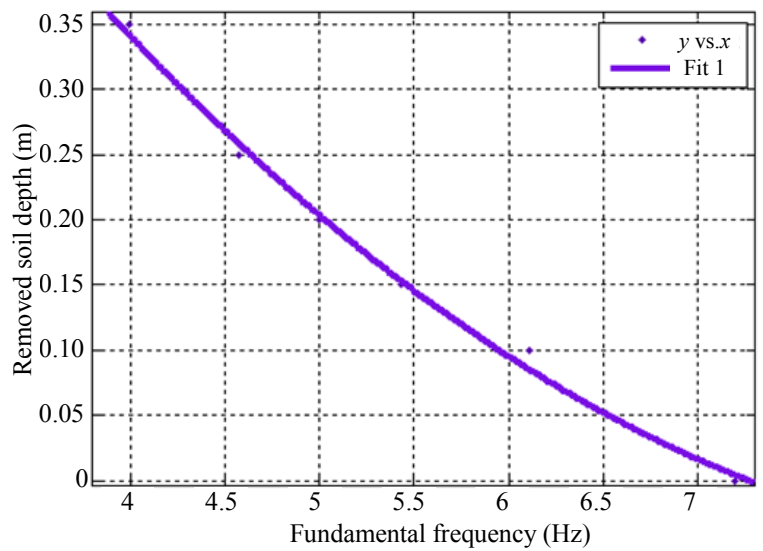

Fig. 11 Relationship between removed depth and frequency.

\section{Conclusions}

This paper presents a new method to measure the SSSF value which can help us form an approximate judgment regarding soil properties. The following conclusions can be drawn from current work:

(1) A vibration sensor is designed based on an FBG sensor for measuring the fundamental frequency of the vibration rod. The rod can be assumed as a free cantilever beam which is fixed beneath a certain depth of the soil. So a modification is made when computing the fundamental frequency.

(2) The wavelength change of the FBG sensor is measured by interrogator SM130. The time domain signals could be changed to frequency domain through FFT so as to get the fundamental frequency of the vibration rod.

(3) The Winkler reaction spring model is adopted to analyze the relationship between the fundamental frequency and stiffness of soil. The SSSF is calculated by the frequency-stiffness equation.

The experimental results are almost identical with the theoretical derivation results. It is confirmed that this method can determine the SSSF effectively and approximately judge the properties of soil.

Open Access This article is distributed under the terms of the Creative Commons Attribution 4.0 International License (http://creativecommons.org/licenses/by/4.0/), which permits unrestricted use, distribution, and reproduction in any medium, provided you give appropriate credit to the original author(s) and the source, provide a link to the Creative Commons license, and indicate if changes were made.

\section{References}

[1] E. Winkler, Die lehre von der elasticitaet und festigkeit. Prag, Czech Republic: H. Dominicus, 1867: 1-206.

[2] R. D. Blevins, Formulas for natural frequency and mode shape. New York, USA: Van Nostrand Reinhold, 1979: 1-461.

[3] S. Timoshenko, D. H. Young, and W. Weaver, Vibration problems in engineering. New York, USA: Wiley, 1974: 1-521.

[4] Y. C. Lai, B. Y. Ting, W. S. Lee, and W. R. Becker, "Dynamic response of beams on elastic foundation," Journal of Structural Engineering, 1992, 118(3): 853-858.

[5] J. Wang, "Vibration of stepped beams on elastic foundations," Journal of Sound \& Vibration, 1991, 149(2): 315-322.

[6] S. Kukla, "Free vibration of stepped beams on elastic foundations," Journal of Sound \& Vibration, 1991, 149: 259-265.

[7] D. Thambiratnam and Y. Zhuge, "Free vibration analysis of beams on elastic foundation," Computers \& Structure, 1996, 60(6): 971-980.

[8] D. Thambiratnam and Y. Zhuge, "Dynamic analysis of beams on an elastic foundation subjected to moving loads," Journal of Sound \& Vibration, 1996, 198(2): 149-169.

[9] R. Zhong and M. S. Huang, "Winkler model for dynamic response of composite caisson-piles foundations: lateral response," Soil Dynamics \& Earthquake Engineering, 2014, 66(13): 241-251.

[10] D. Y. Gao, J. Machalová, and H. Netuka, "Mixed finite element solutions to contact problems of nonlinear Gao beam on elastic foundation," Nonlinear Analysis: Real World Applications, 2015, 22: 537-550.

[11] M. Hajialilue-Bonab, D. Levacher, J. L. Chazelas, and A. M. Kaynia, "Experimental study on the dynamic behavior of laterally loaded single pile," Soil Dynamics \& Earthquake Engineering, 2014, 66: $157-166$.

[12] A. Zarafshan, A. Iranmanesh, and F. Ansari, "Vibration-based method and sensor for monitoring of bridge scour," Journal of Bridge Engineering, 2012, 17(6): 829-838.

[13] H. F. Pei, J. H. Yin, H. H. Zhu, C. Y. Hong, and Y. H. Fan, "In-situ monitoring of displacements and 
stability evaluation of slope based on fiber Bragg grating sensing technology," Chinese Journal of Rock Mechanics and Engineering, 2010, 29(8): 1570-1576.

[14] H. H. Zhu, J. H. Yin, W. Jin, and T. M. K. Kuo, "Health monitoring of foundations using fiber Bragg grating sensing technology," China Civil Engineering Journal, 2010, 43(6): 109-115.

[15] H. H. Zhu, B. Shi, J. F. Yan, C. Chen, Y. Li, J. Wang, et al., "Physical model testing of slope stability based on distributed fiber-optic strain sensing technology," Chinese Journal of Rock Mechanics and Engineering, 2013, 32(4): 821-828.

[16] C. Rodrigues, F. Cavadas, C. Félix, and J. Figueiras, "FBG based strain monitoring in the rehabilitation of a centenary metallic bridge," Engineering Structures, 2012, 44(6): 281-290.

[17] Z. Zhou, M. H. Huang, L. Q. Huang, J. P. Ou, and G. D. Chen, "An optical fiber Bragg grating sensing system for scour monitoring," Advances in Structural Engineering, 2011, 14(1): 67-78.

[18] D. S. Li, L. Ren, H. N. Li, and G. B. Song, "Structural health monitoring of a tall building during construction with fiber Bragg grating sensors," International Journal of Distributed Sensor Networks, 2012, 2012: 272190-1-272190-10.

[19] C. L. Wei, C. C. Lai, S. Y. Liu, W. H. Chung, T. K. Ho, H. Y. Tam, et al., "A fiber Bragg grating sensor system for train axle counting," IEEE Sensors Journal, 2010, 10(12): 1902-1912.

[20]C. L. Wei, Q. Xin, W. H. Chung, S. Y. Liu, H. Y. Tam, and S. L. Ho, "Real-time train wheel condition monitoring by fiber Bragg grating sensors," International Journal of Distributed Sensor Networks, 2012, 2012(1550-1329): 47-54.

[21] H. F. Pei, J. H. Yin, H. H. Zhu, C. Y. Hong, W. Jin, and D. S. Xu, "Monitoring of lateral displacements of a slope using a series of special fiber Bragg grating-based in-place inclinometers," Measurement Science and Technology, 2012, 23(2): 025007-1-025007-8.

[22] H. F. Pei, J. H. Yin, and W. Jin, "Development of novel optical fiber sensors for measuring tilts and displacements of geotechnical structures," Measurement Science and Technology, 2013, 24(9): 095202.

[23] G. Kister, D. Winter, Y. M. Gebremichael, J. Leighton, R. A. Badcock, P. D. Tester, et al., "Methodology and integrity monitoring of foundation concrete piles using Bragg grating optical fibre sensors," Engineering Structures, 2007, 29(9): 2048-2055.

[24] X. W. Ye, Y. H. Su, and J. P. Han, "Structural health monitoring of civil infrastructure using optical fiber sensing technology: a comprehensive review," The Scientific World Journal, 2014: 652329-1652329-11.

[25] F. Ansari, "Fiber optic sensors for structural health monitoring of civil infrastructure systems," Structural Health Monitoring of Civil Infrastructure Systems, 2009: 260-282.

[26] R. Clough and J. Penzien, Dynamics of structure. Berkeley, CA, USA, Computers and Structures, 1995: $1-729$. 